\title{
Visual Media To Campaign The Sexual Health For Teenagers

\author{
(Study Case Using Visual Media To Inform Health \\ Reproduction For Teenager In Solo )
}

\author{
Esty Wulandari \\ Visual Design Communication, Faculty of Arts and Design, Sebelas Maret University \\ Jalan Ir.Sutami No 36 A,Surakarta-Indonesia \\ febeesty@gmail.com
}

\begin{abstract}
More than 50\% of the world's population begins their sexual activity in their youth. empowering adolescents to improve their sexual health can help them effectively deal with related problems, such as infertility, sexually transmitted infections, and highrisk sexual behaviors; it can also encourage the younger generation to rationally approach and take responsibility for sexual relations. Sexual health education programs are necessary for individuals who have not yet begun engaging in sexual activities and those who are already sexually active. Sexual health education is "a lifelong process of acquiring information and forming attitudes, beliefs, and values about such important topics as identity, relationships, and intimacy". Despite its importance for adolescents, sexual health education is a complex endeavor.The methods of the research using qualitative study, in-depth interviews with ten key informants and five focus group discussions involving teenager aged 12-18 were conducted. All the discussions were audio-recorded and later transcribed. The data were classified, after which the main themes and sub-themes were manually extracted and analyzed.

By using uisual media to campaign about sexual health reproduction, it has important role to right information about sexual health education to the teenager. It will give full information that the teenager needs about sexual reproduction. Good information about sexual health education needs to do. The Department of Health in Solo doing visual media to explain about the teenager about it. The used puzzle games that contains of the function of sexual reproduction male and female, brochure that give information about how to keep their health of the sexual reproduction, flashcards game about sexual reproduction that they used in groups, edutainment game, using of film explains about the organ of sexual reproductions. The results showed that using visual media to inform about sexual health education is important. Tailored educational programs, based on teenagers' views, had been developed and implemented.
\end{abstract}

Keywords: Visual media,Campaign, Sexual Health Reproduction,

\section{INTRODUCTION}

Adolescence marks the period between childhood and adulthood, when hormonal changes transforms boys and girls into young men and woman and able to have children of their own. The percent of adolescence who are having sex at earlier ages has decreased since 1990 and contraceptive use has increased since 2000s. Together these two factors have contributed to the indonesia reaching its lowest teen pregnancy and birth rates in years.

Indonesia`s adolescent population stands at about 45,8 million or 13,3 percent of its 259 million population.It is to be concern of the government, because many cases happens during this age. Departement of Health of Indonesia try to develop this problem, to make the teenager keep their sexual reproduction. Cases that often happens in teenager such as free sex, teen marriage, unwanted pregnancies, sexual violence, HIV, AIDS and other sexual disease.It happens because they dont understand their sexual activity will be impact to the health of sexual reproduction. Women's reproductive health have undergone transformation from psychoanalytic and psychosomatic models focusing on women's unconscious and defensive processes as determinants of adverse outcomes to models underscoring the multiply determined and individually variable nature of reproductive experiences.(Annete, $2002: 751$ )

Their environment has impact to the teenager, such as the influence of their friends at school, their family, media, internet, etc, The internet that contains of porn, can influence the sexual activity of the teenager too. Teenager with 12 until 22 years old, has potential to be influenced with it. Most young people quench their curiosity about sex through pornography found on the internet, porn magazines and tall tales told by friends. Teen are not children; nor are they adults. They tend to not to give positive feedback easily as cjildren and as general rule they are kess articulate and forthcoming about what they need than adults.(Jane Halsall,2009:7)

Health communication program is seeking influence and engage in the communication process, also reffered to as target audiences. Communication has its roots in people`s need to share and transmit meaning and ideas (Renata, 2007 :5). It means that using communication it can share information about sexual health reproductive properly. Coomunication aims to improve health outcomes by sharing health-related information. Using Visual media

\section{METHODOLOGY}

This paper applies a qualitative research method depending on observation, documentation, literature study through phenomenology documentation. The information collections such as as visual data and secondary data are gathered. 
Framework of this research as below :

\begin{tabular}{|c|}
\hline Problem of youth : \\
\hline Sexual Reproductive Health \\
\hline Management \& Program Health Communication \\
\hline $\begin{array}{c}\text { Using Visual Communication Media } \\
\text { Komunikasi Visual to give good information } \\
\text { about Sexudl Reproductive Health }\end{array}$ \\
\hline $\begin{array}{c}\text { Sosialization to the youth did by Departement of } \\
\text { health Surakarta cooperation with Community } \\
\text { empowerment (Bapermas P3AKB) }\end{array}$ \\
\hline
\end{tabular}

\section{RESULTS}

They learn the facts about sexual health with visual communication about puberty, mestruation, infection and just about everything else they wanted to know for boys and girls. Using visual comunication media to share Sexual Reproductive Health information.

a. Situation analysis

According to the Balitbang BKKN of Central Java Province, states that in adolescence can experience a critical age and prone to problems, especially reproductive health problems. Even from the IDHS data in 2003, stated that teenage knowledge about reproductive health is still low. Even the abortion rate in Indonesia is still quite high, which is around $80 \%$ is teenagers. (UNFPA \& Bapenas, 2009). Adolescents as assets and the next generation of the nation are lacking information about reproductive health properly. Even what happened was that information about reproductive health received by teenagers confusing and even misleading.

\section{b. Communication Objective}

The teenagers must have awareness of the importance of maintaining reproductive health with the right information.

c. Communication Strategy

As Communication services, they had Adolescent Reproductive Health Information and Counseling Center from the Health Service with Adolescent Health Care Services Surakarta.

Data obtained from the Mahardika Surakarta PIK (Reproductive Health Information and Counseling Center to be reproductive health problems programs carried out by the government through BKKBN is through the Establishment of PIKKR (Information Center for Adolescent Reproductive Health Counseling).

d. Target Audience of Sexual Reproductive Health

As making communication program, it needs to be understood who is the target of the Adolescent
Reproductive Health Campaign, as stated by Dr.Slamet Riyanto, Health and Elderly Section that Teenagers are dynamic growth or the transition period from children to teenagers. There is a process of physical, mental and spiritual growth. In adolescence, there are a lot of irregularities because teenagers often try it.

a. Using Media Visual Communication to share about

Sexual Reproductive health :

\section{Puzzle game}

Using Puzzle Games about the male and female reproductive system. Arranging puzzle pieces iby looking at the overall picture first, then the teenagers asked to compile one by one pieces of this puzzle.

2. Flash cards

Flash cards as tools for providing information about reproductive and their functions which are made simpler and easier to understand.

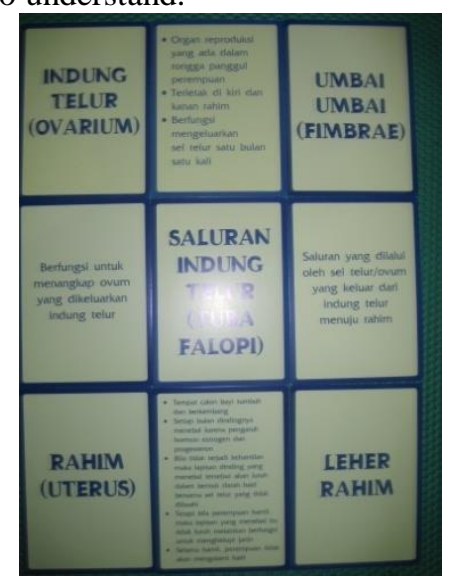

3. Brochures, folders, leaflets or pamphlets

Brochures, folders, leaflets or pamphlets provides accurate and honest information to improve teen sexual health, as well as various ways for adolescents to get involved in various campaigns around sexual and reproductive health. The dissemination of this media was carried out by Bapermas AA and $\mathrm{KB}$, to junior and senior high school education levels through youth groups located in each sub-district in Surakarta.

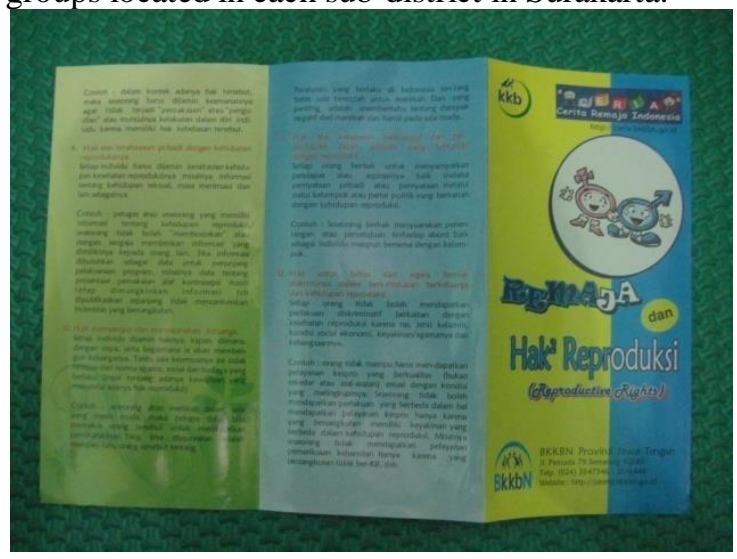

4. Guide Book about Adolescent Reproductive Health The existence of a guidebook about Adolescent Reproductive Health provided to facilitators. 


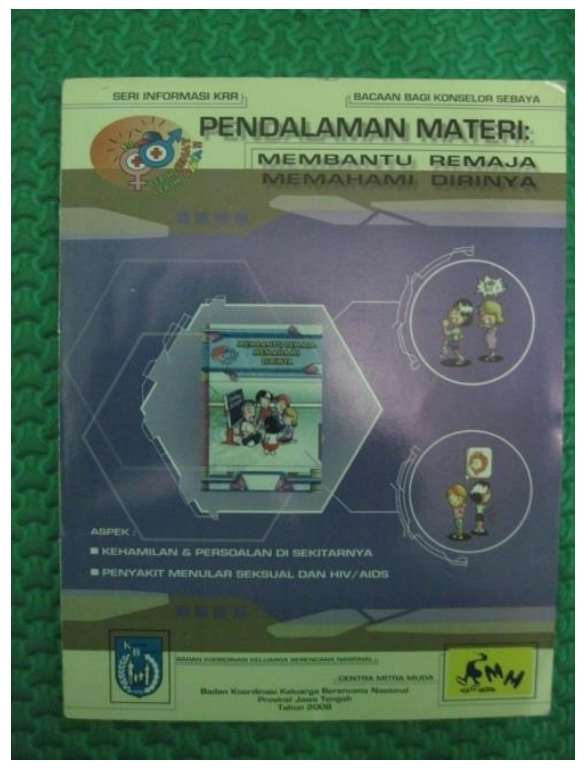

5. Edutainment video about Teenage Reproductive Health. Audio visual

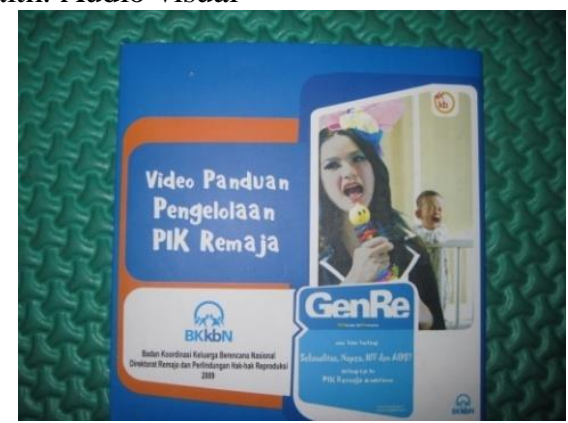

\section{SUGGESTION}

It is important that government works together with civil society, private sector, including NGOs and young networks to fulfill the needs of all young people, particularly on sensitive issues such as sexual and reproductive health. It is a taboo topic that is never discused at home or taught in schools but really needed to the youth, it is ptovided outlets of information and service provisions exist for indonesian youth. The message will be created with good visuality as a message not only focus on physical things such as prevention of sexual transmission infection or family planning, topics that may not resonate with youth, Instead, educators or advocates should link Sexual Reproductive Health with topic related to boosting youth1s self-worth, self esteem and feeling good about their bodies, their futures and developing healthy relationship with female and male friends. Failing to meet the needs of Indonesia`s younger generation in providing Sexual Reproductive Health information may lead to increasing numbers of unwanted pregnancies, teen marriages and sexual violences. They must be given wide acces to information through visual communication and knowledge on reproductive health and family planning services. Youth, must be involved grom the very beginning as problesm solvers and architects of solutions rather than just as beneficiaries. With that, Indonesia will have healthy, well-educated, and well-informed youth and the economic returns will huge. Indonesia will be able to reap its demographic dividend in the coming years.

\section{REFERENCE}

Annette L. Stanton, Marci Lobel,(2002), Psychosocial Aspects of Selected Issues in Women's Reproductive Health:Current Status and Future Directions, Journal of Consulting and Clinical Psychology, The American Psychological Association, USA.

John Halsall, R.william E,(2009), Visual Media for Teens, ABC-CLIO,LLC, USA

Renata Schiavo, (2007),Health Communication : From Theory to Practice, John Wiley \& Sons, USA 